\title{
Bioengineered in vitro tissue model of fibroblast activation for modeling Pulmonary Fibrosis
}

Aswin Sundarakrishnan ${ }^{1}$, Heather Zukas ${ }^{1}$, Jeannine Coburn ${ }^{1,5}$, Brian T. Bertini', Zhiyi Liu ${ }^{1,6}$, Irene Georgakoudi ${ }^{1}$, Lauren Baugh ${ }^{1}$, Queeny Dasgupta ${ }^{1}$, Lauren D. Black ${ }^{1,4}$ and David L. Kaplan ${ }^{1, *}$

${ }^{1}$ Department of Biomedical Engineering, Tufts University, 4 Colby Street, Medford, MA,

${ }^{3}$ Department of Chemical and Biological Engineering, Tufts University, 4 Colby Street, Medford, MA,

${ }^{4}$ Department of Cell, Molecular \& Developmental Biology, Sackler School of Graduate Biomedical Sciences, Tufts University, 136 Harrison ave., Boston, MA,

${ }^{5}$ Department of Biomedical Engineering, Worcester Polytechnic Institute, 60 Prescott Street, Worcester, $M A$,

${ }^{6}$ Wellman Center for Photomedicine, Massachusetts General Hospital, 40 Blossom St, Boston, MA.

\section{*Corresponding Author:}

David L. Kaplan, PhD

Department of Biomedical Engineering

Tufts University

4 Colby Street

Medford, MA 02155

david.kaplan@tufts.edu

Details of supporting information

Number of pages: 14

Number of supporting figures: 12

Number of supporting tables: 1 


\begin{tabular}{|c|c|c|c|}
\hline \multicolumn{4}{|c|}{ Silk-collagen-type I hydrogel } \\
\hline \multirow[b]{2}{*}{ \# } & Volume & $1000 \mu \mathrm{l}$ & \\
\hline & Reagent & Final Concentration/Volume & \begin{tabular}{|l} 
Sequence \\
of \\
Addition
\end{tabular} \\
\hline 1 & Silk & $2 \%(\mathrm{w} / \mathrm{v})$ & 4 \\
\hline 2 & $\begin{array}{l}\text { High concentration rat tail } \\
\text { type I collagen }\end{array}$ & $1 \mathrm{mg} / \mathrm{ml}$ & 5 \\
\hline 3 & $1 \mathrm{M} \mathrm{NaOH}$ & $0.023 *$ volume of collagen-I & 3 \\
\hline 4 & 1x DMEM & $0.5 x$ & 1 \\
\hline 5 & Cell suspension & $50 \mu 1$ & 8 \\
\hline 6 & $\begin{array}{l}\text { Horseradish peroxidase } \\
\text { (HRP) }\end{array}$ & $10 \mu \mathrm{l}$ of $1000 \mathrm{U} / \mathrm{ml}$ & 6 \\
\hline 7 & $\mathrm{H}_{2} \mathrm{O}_{2}$ & $10 \mu \mathrm{l}$ of $1.65 \mathrm{mM}$ & 7 \\
\hline 8 & Water & $\operatorname{Sum}(1-7)-1000 \mu 1$ & 2 \\
\hline
\end{tabular}

Collagen type-I hydrogel

\begin{tabular}{|c|c|c|c|}
\hline \multicolumn{2}{|r|}{ Volume } & \multicolumn{2}{|l|}{$1000 \mu \mathrm{l}$} \\
\hline \# & Reagent & Final Concentration/Volume & $\begin{array}{l}\text { Sequence } \\
\text { of } \\
\text { Addition }\end{array}$ \\
\hline 1 & $\begin{array}{l}\text { High concentration rat tail } \\
\text { type I collagen }\end{array}$ & $1 \mathrm{mg} / \mathrm{ml}$ & 4 \\
\hline 2 & $1 \mathrm{M} \mathrm{NaOH}$ & $0.023 *$ volume of collagen-I & 3 \\
\hline 3 & 1x DMEM & $0.5 \mathrm{x}$ & 1 \\
\hline 4 & Cell suspension & $50 \mu 1$ & 5 \\
\hline 5 & $\begin{array}{l}\text { Horseradish peroxidase } \\
\text { (HRP) }\end{array}$ & $10 \mu 1$ of $1000 \mathrm{U} / \mathrm{ml}$ & 6 \\
\hline 6 & $\mathrm{H}_{2} \mathrm{O}_{2}$ & $10 \mu 1$ of $1.65 \mathrm{mM}$ & 7 \\
\hline 7 & Water & $\operatorname{Sum}(1-6)-1000 \mu 1$ & 2 \\
\hline
\end{tabular}

Table S1: Procedure and formulation for preparing silk-collagen-type I and collagen-type I hydrogels for pulmonary cell encapsulation. 

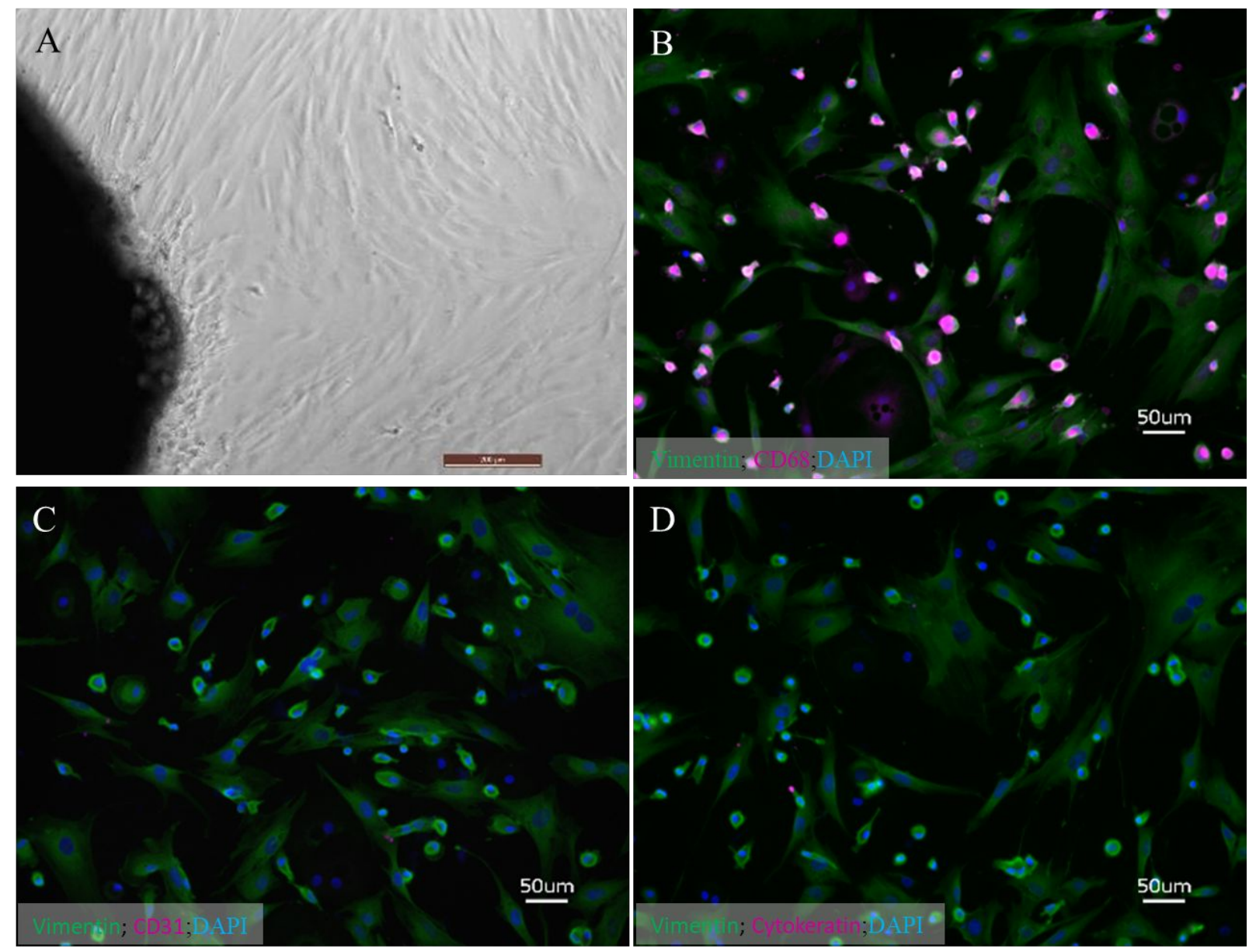

Figure S1: Culture and phenotypic confirmation of normal pulmonary fibroblasts isolated from human lung explants (A) fibroblast cells growing out of lung explants. (B) CD68 immune cells commixed with vimentin ${ }^{+}$pulmonary fibroblasts before purification. (C) absence of CD31 $1^{+}$ endothelial cells among vimentin ${ }^{+}$fibroblasts. (D) absence of pan cytokeratin ${ }^{+}$epithelial cells among vimentin ${ }^{+}$fibroblasts. 


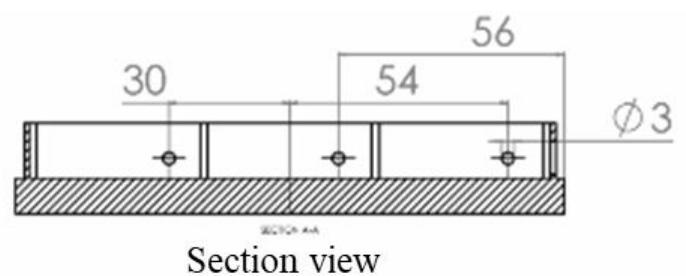

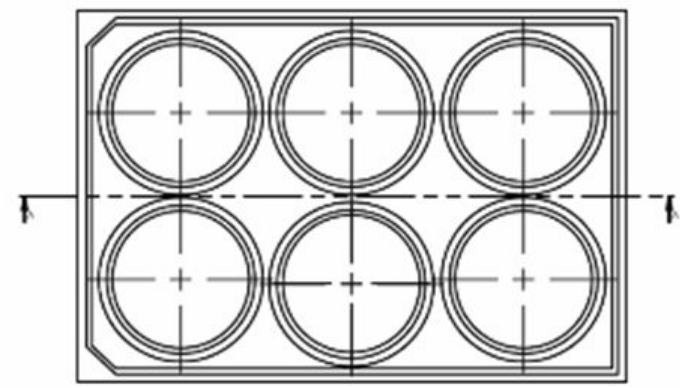

Top view

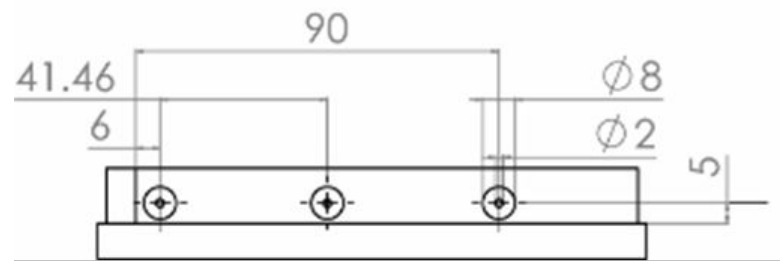

Side view 1

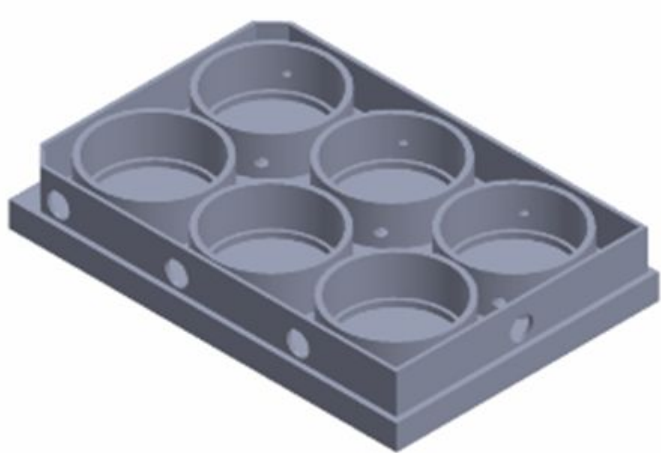

Isometric view

Figure S2: Section and Isometric views of customized Flexcell® Tissue Train ${ }^{\circledR}$ bioreactor. 


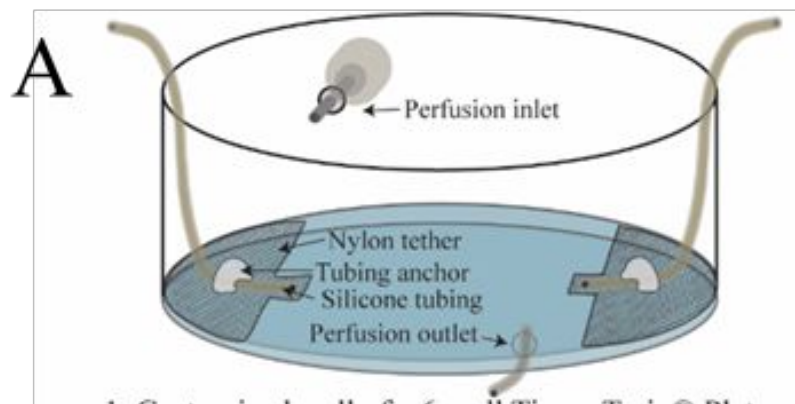

1. Customized well of a 6-well Tissue Trainß Plate

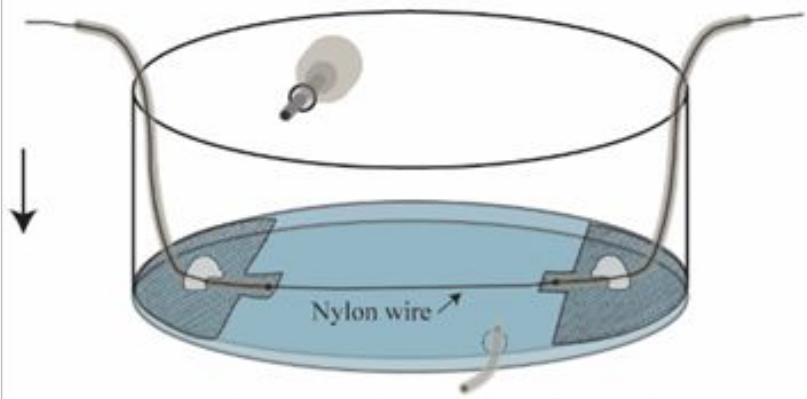

2. Nylon wire is threaded through silicone tubing

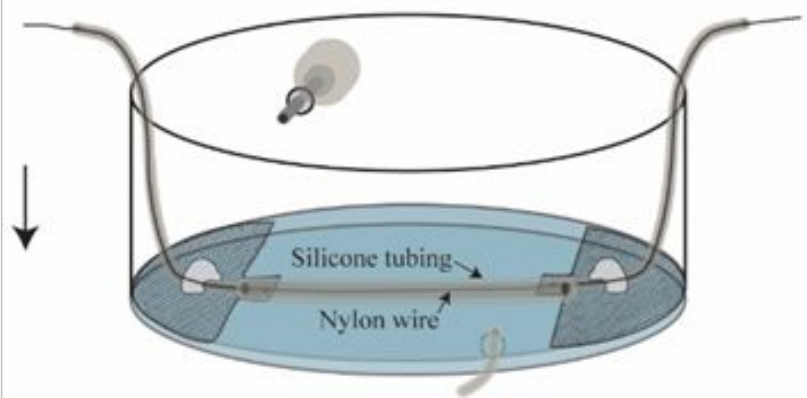

3. Silicone tubing is placed outside nylon wire to form mold

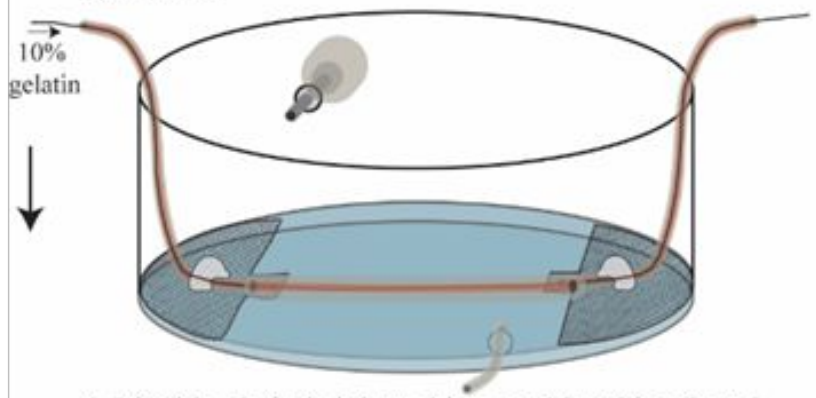

4. Liquid gelatin is injected into mold and incubated in $4^{\circ} \mathrm{C}$

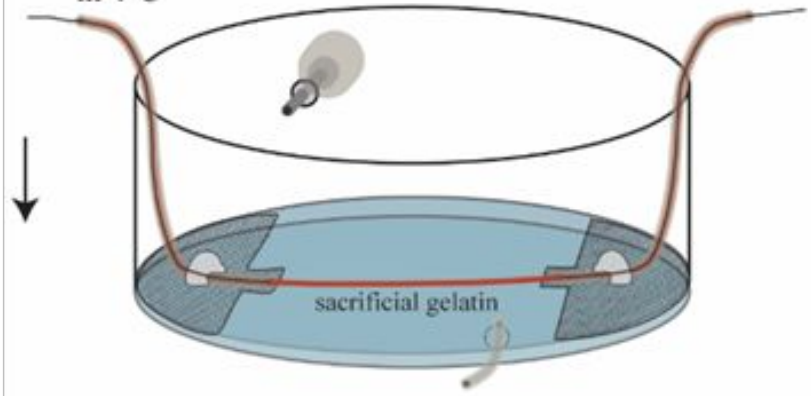

5. Silicon tubing mold is removed leaving behind tubular sacrificial gelatin

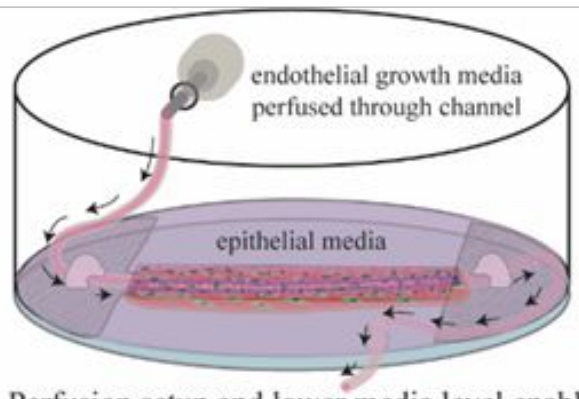

10. Perfusion setup and lower media level enables air-liquid interface culture of epithelial cells

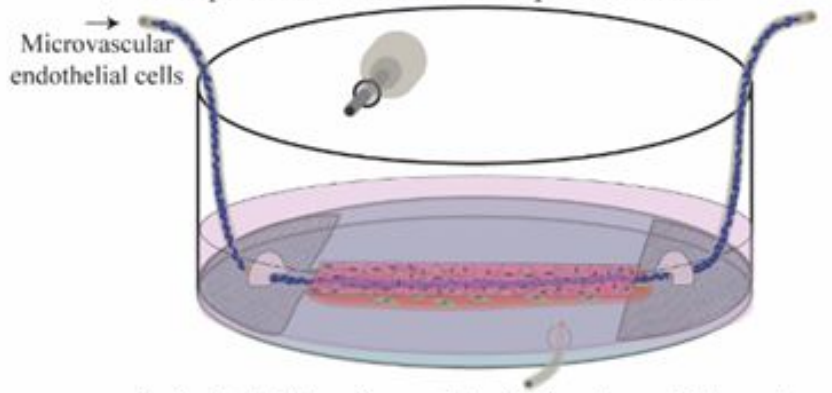

9. Endothelial cells seeded within channel through silicone tubing

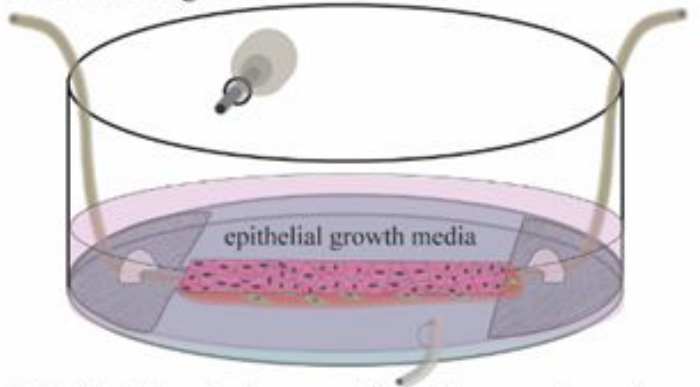

8. Epithelial cells form confluent layer on top of scaffold after stencil removal

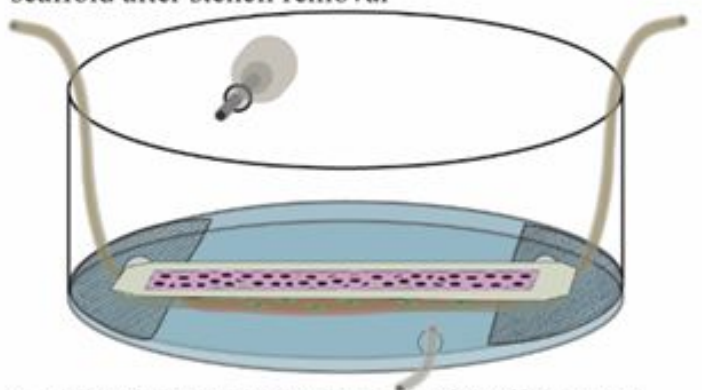

7. Epithelial cells seeded on top of scaffold using custom silicone stencil

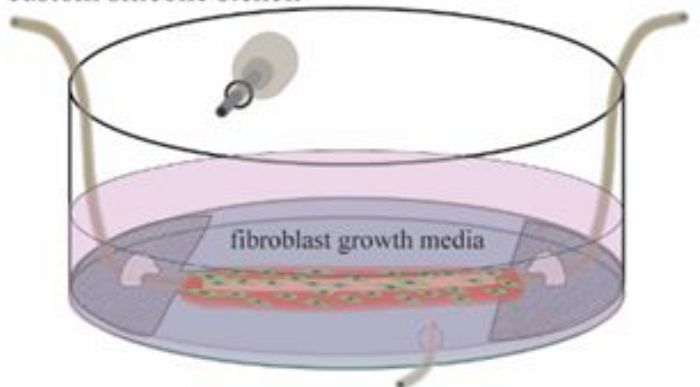

6. Silk-collagen-I hydrogel solution with fibroblasts added around gelatin and incubated at $37^{\circ} \mathrm{C}$ to form scaffold with channel 
Step 1: Machined Flexcell plates were modified by attaching $3 \mathrm{~cm}$ long silicone tubing Outer diameter (OD): $0.635 \mathrm{~mm}$; Inner diameter (ID): $0.305 \mathrm{~mm}$ (McMaster carr, Elmhurst, IL) onto nylon tethers on either side using instant UV light curing adhesive Loctite 4307 (Krayden Inc., Denver, CO) and drier for 1 hour. After drying plates were sterilized by immersing in $70 \%$ ethanol overnight under UV lamp inside a Biosafety Level - 2 (BSL-2) tissue culture hood.

Step 2-5: To create straight channels within the hydrogels, a monofilament nylon fishing line OD: $0.2 \mathrm{~mm}$ was threaded through silicone tubing. Silicone tubing of relatively larger diameter (ID: $0.635 \mathrm{~mm}$; OD: $1.193 \mathrm{~mm}$ ) enclosed the nylon wire to form a mold. Molten $10 \%(\mathrm{w} / \mathrm{v})$ porcine gelatin (Sigma-Aldrich, St. Louis, MO) in $0.5 \times D M E M$ was perfused through the silicone tubing and allowed to solidify at $4^{\circ} \mathrm{C}$.

Step 6: Primary human lung fibroblasts $\left(1 \times 10^{6}\right.$ cells $\left./ \mathrm{ml}\right)$ were mixed in a solution of $2 \%$ silk-collagen-type I and crosslinked using $\mathrm{HRP}$ and $\mathrm{H}_{2} \mathrm{O}_{2}$ around the sacrificial gelatin hydrogel. Flexcell plates were placed at $37^{\circ} \mathrm{C}$, resulting in melting of gelatin and crosslinking of silk-collagen-type I hydrogel at the same time.

Step 7-8: A silicone stencil was used and epithelial cells $\left(2 \times 10^{6}\right.$ cells $/ \mathrm{ml}$ ) were seeded on top of the silk-collagen-type I hydrogel construct. Media within the Flexcell plates was switched to Minimum Essential Media with 10\% FBS and 1x Penn/Strep. Epithelial cells formed a confluent layer on top of the hydrogel construct in 3 days.

Step 9-10: Endothelial cells $\left(2 \times 10^{6}\right.$ cells $\left./ \mathrm{ml}\right)$ were perfused through silicone tubing into the channel within the hydrogel. Endothelial cells were seeded both on top and bottom of the hydrogel channel, by incubating Flexcell plates both upright and upside down orientations. After 24 hours of endothelial seeding, silicone tubing was connected to a syringe pump to allow for perfusion culture.

Figure S3: Modification of Flexcell bio-reactor for perfusion (A) Illustration of sequential steps (1 to 10) involved in creating a microchannel within silk-collagen-type I hydrogels with pulmonary cells. 

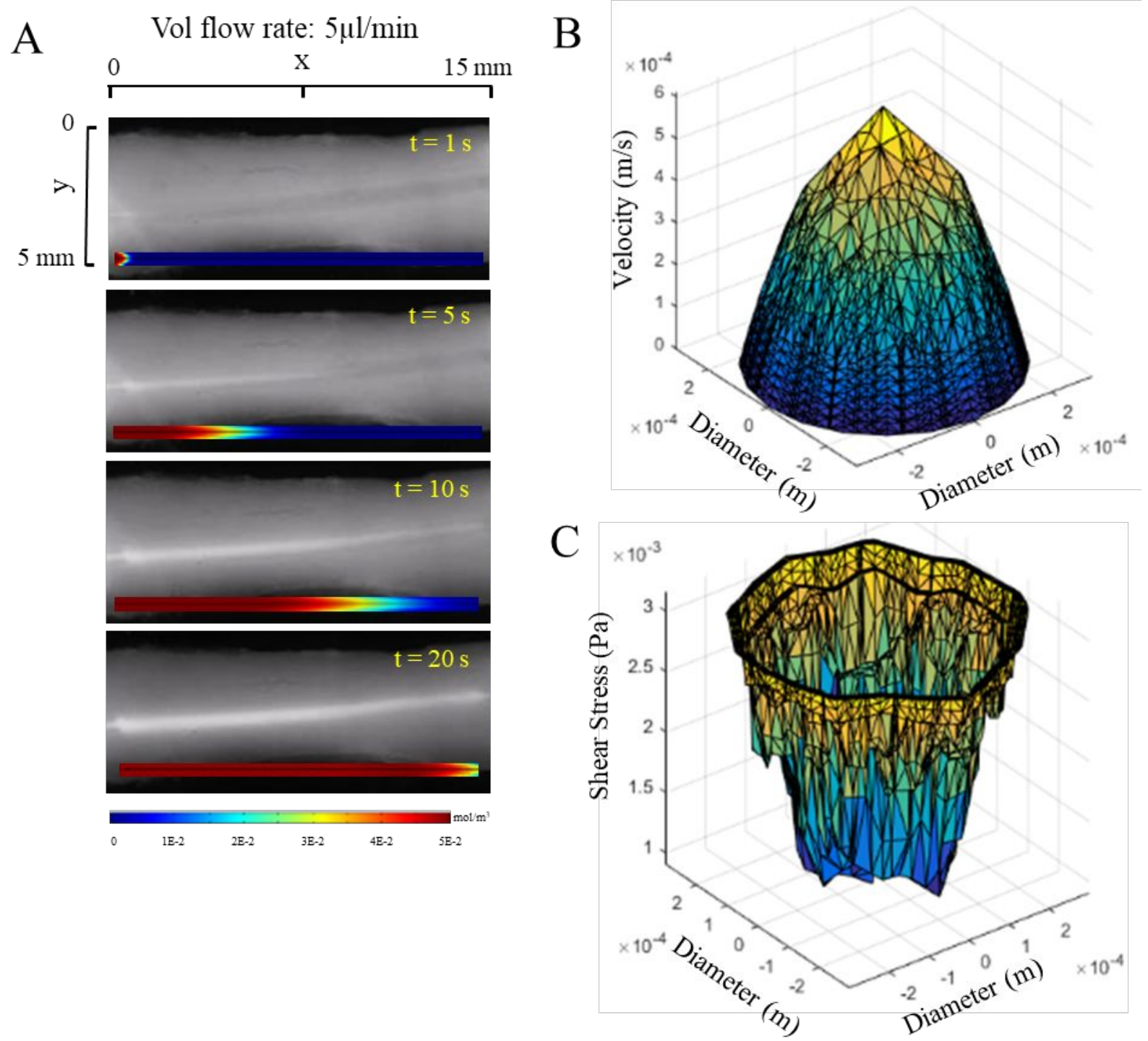

Figure S4: Flow profile and shear stress in Eng-PF (A) Laminar flow profile of FITC-Dextran observed within hydrogel channel confirms 3D FEM mathematical models. (B) Surface plot of laminar flow profile shows maximum and zero velocity at channel center and wall respectively. (C) Surface plot of shear stress shows maximum and zero shear stress at channel wall and center respectively. 

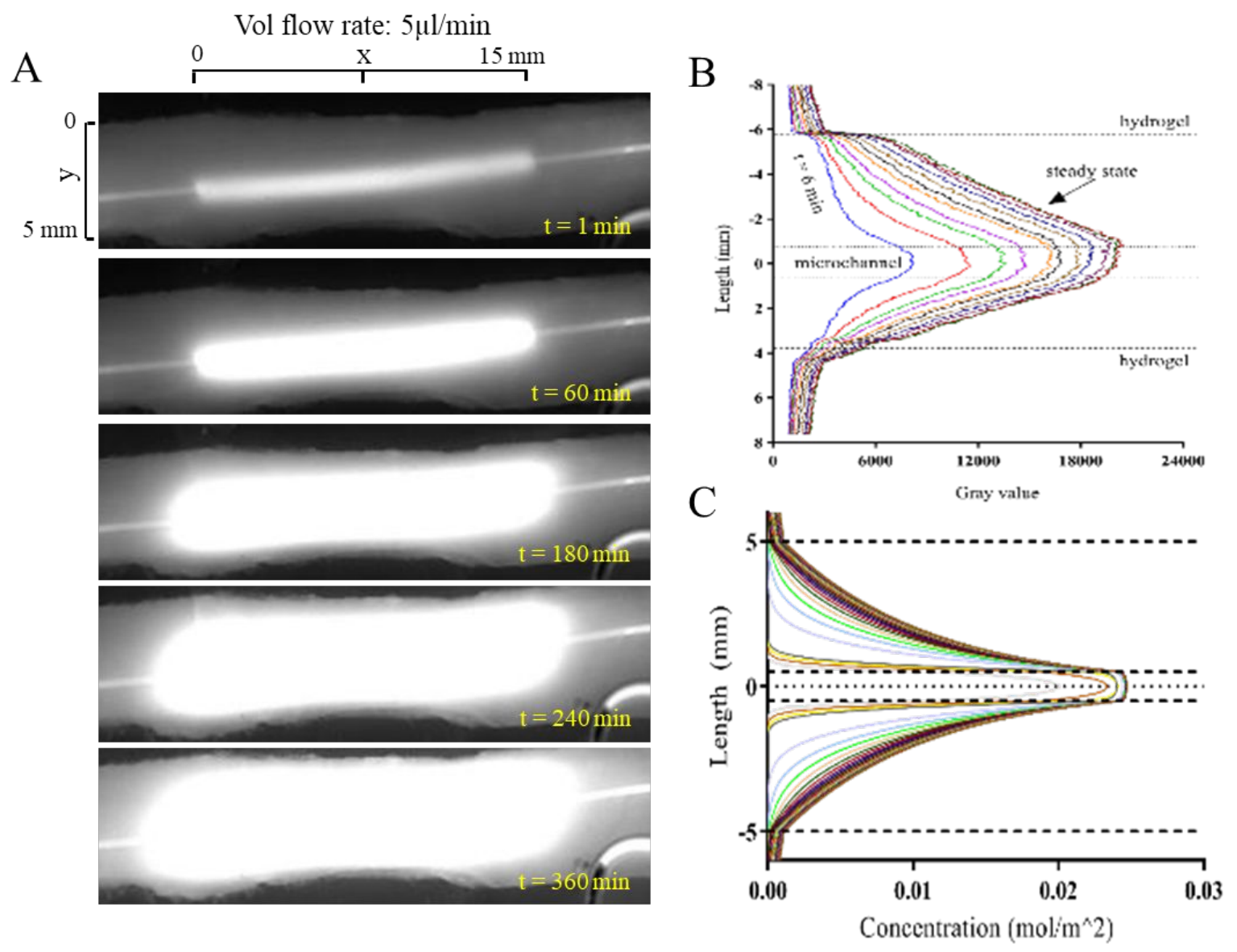

Figure S5: Characterization of diffusion within engineered hydrogels (A) Evolution of FITCDextran $(\mathrm{D}=6.4 \times 10-10 \mathrm{~m} 2 \mathrm{~s}-1)$ diffusion profile confirms 3D FEM mathematical models. (B) Fluorescence intensity profiles of FITC-Dextran along hydrogel y-axis for 6 hours in 30-minute increments. (C) FEM simulations predict a similar evolution of diffusion profile with time and steady state. 

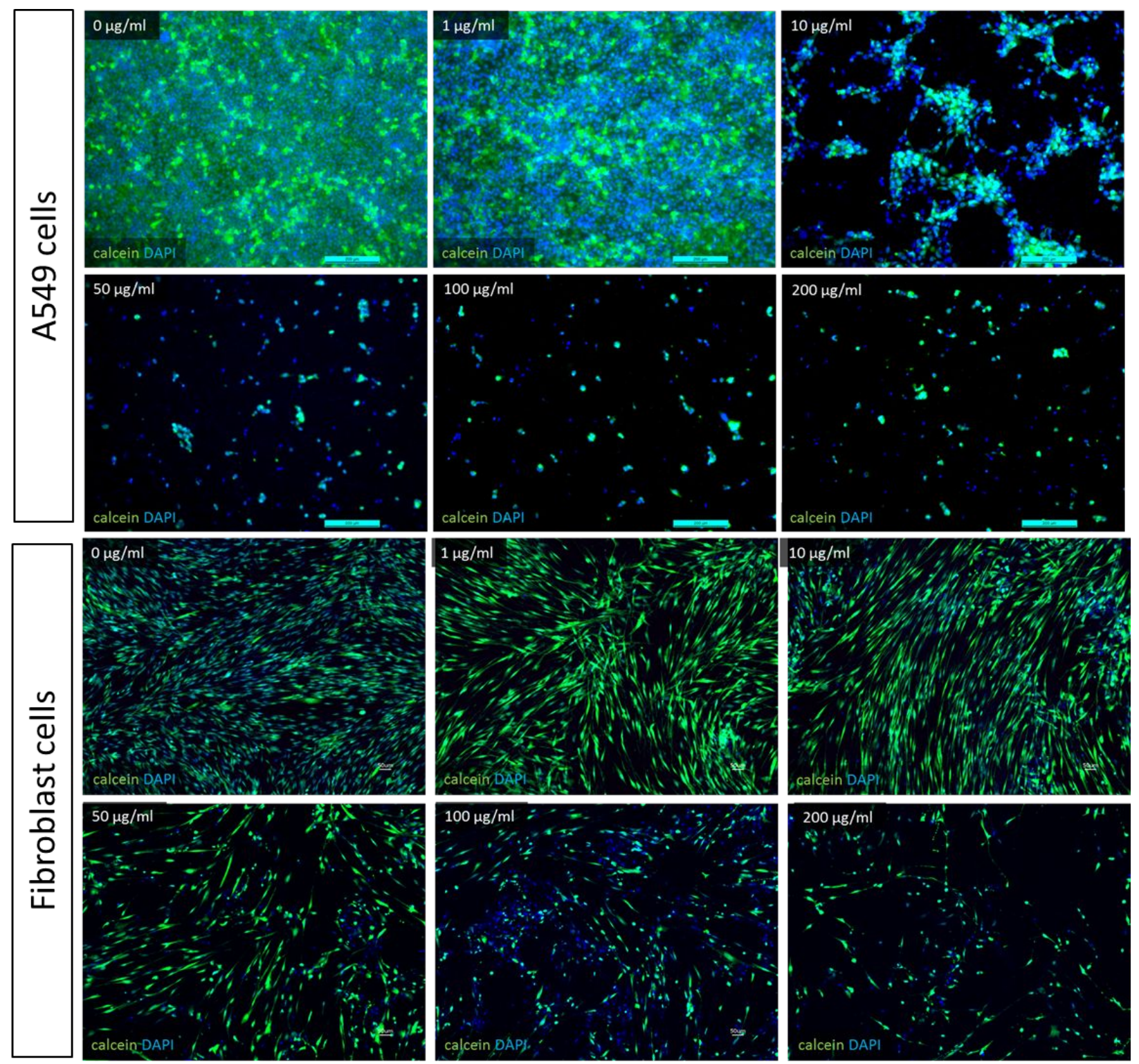

Figure S6: Dose dependent toxicity of bleomycin on A549 and fibroblast cells cultured on tissue culture plastic (TCP). A549 monolayers were disrupted with the addition of $10 \mu \mathrm{g} / \mathrm{ml}$ bleomycin and significantly reduced calcein positive cells were observed. In comparison, a $10 \mu \mathrm{g} / \mathrm{ml}$ bleomycin dosage did not affect the fibroblast monolayer and higher dosages of bleomycin $(>50$ $\mu \mathrm{g} / \mathrm{ml}$ ) was required to disrupt the fibroblast monolayer. 

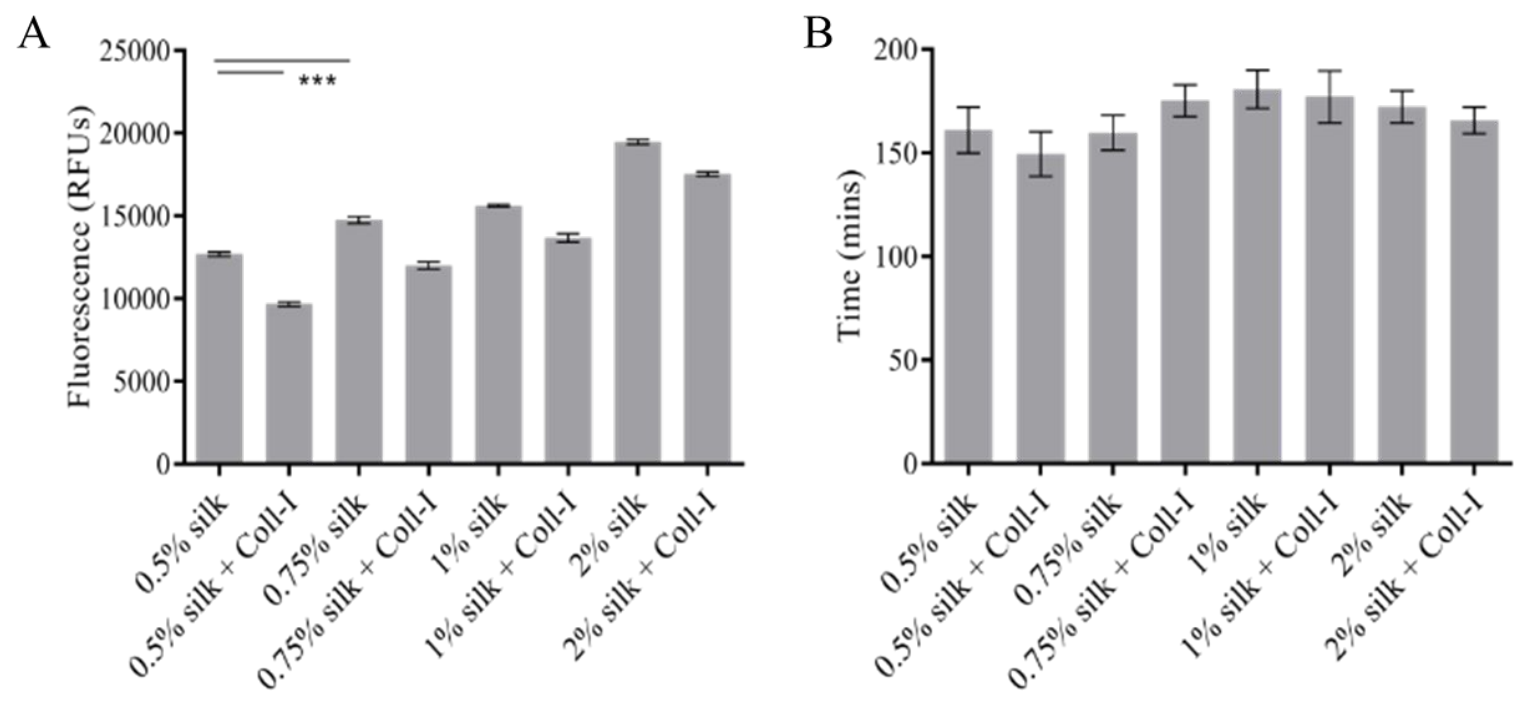

Figure S7: Di-tyrosine crosslinking kinetics of silk-collagen-type I hydrogels (A) Di-tyrosine fluorescence maxima shows silk-collagen-type I hydrogels have significantly lower dityrosine fluorescence intensity compared to concentration matched silk hydrogels. (B) Time taken to reach fluorescence maxima shows no significant different between different groups. $n=4$ /group for dityrosine crosslinking assays.

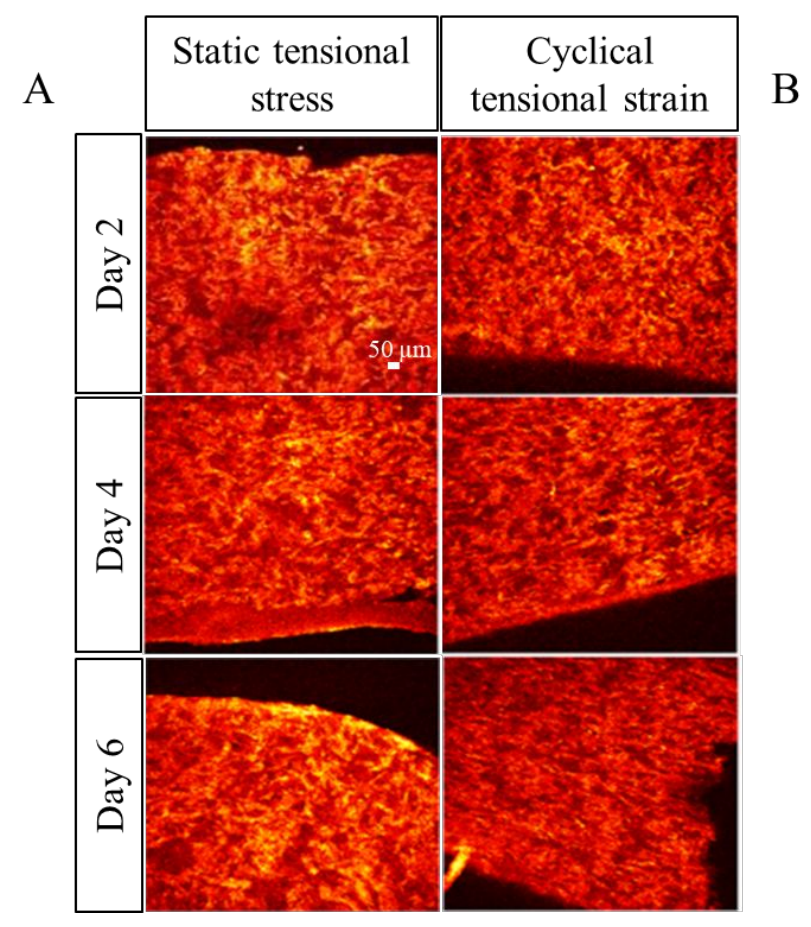

SHG coll-I (Static tensional stress)
SHG coll-I (Cyclical tensional strain)

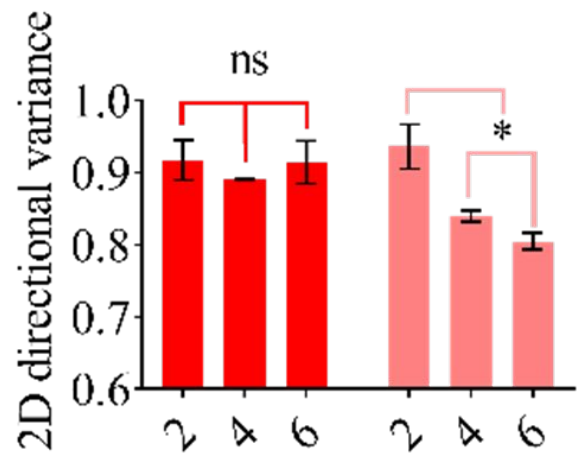

Days 
Figure S8: Collagen fiber orientation in response to cyclical uniaxial strain application $(10 \%$ strain; $0.2 \mathrm{~Hz}$; sinusoidal waveform) (A) Representative SHG images of static and cyclically strained silk-collagen-type I hydrogel constructs at days 2, 4, and 6 of in vitro culture. (B) Twodimensional directional variance shows collagen fiber alignment within cyclically strained constructs. Statically cultured hydrogels maintained a random fiber orientation with no significant change in collagen fiber orientation. $\mathrm{n}=2$ /group.

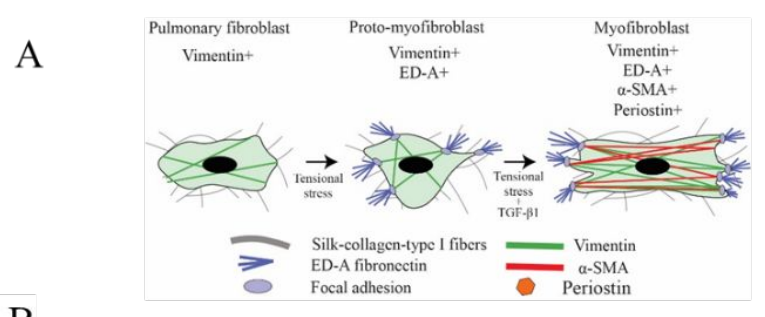

B

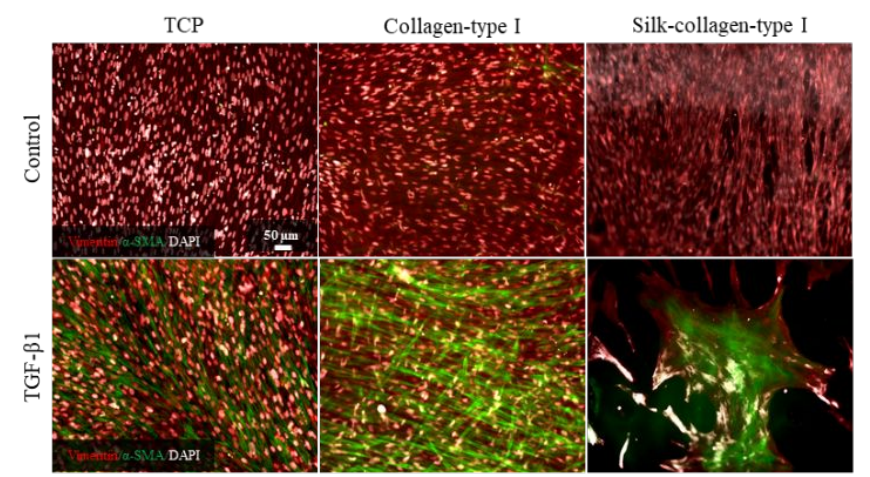

$\mathrm{C}$

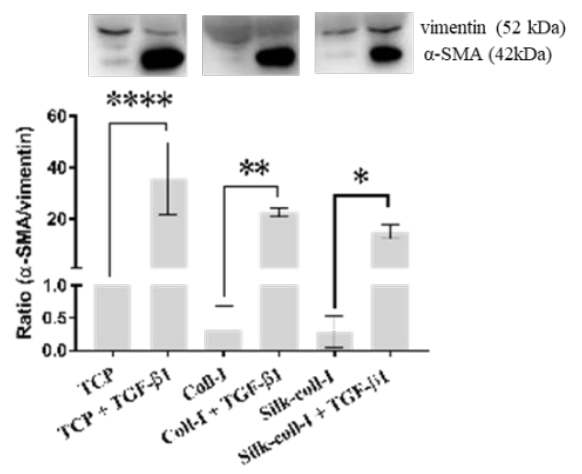

Supplementary figure 8: Fibroblast phenotype after 2-week two-dimensional (2D) culture on TCP, collagen-type I and silk-collagen-type I hydrogels (A) Schematic illustration of fibroblast phenotype during 2D culture (B) Fluorescence immunohistochemistry showing robust induction of myofibroblast phenotype following TGF- $\beta 1$ treatment (C) Western blotting and densitometry provide quantitative validation of myofibroblast differentiation $\left(\alpha-\mathrm{SMA}^{+}\right)$only in the presence of TGF- $\beta 1$ cytokine. $\mathrm{n}=3$ /group.

Figure S9: Fibroblast phenotype after 2-week two-dimensional (2D) culture on TCP, collagentype I and silk-collagen-type I hydrogels (A) Schematic illustration of fibroblast phenotype during 2D culture. (B) Fluorescence immunohistochemistry showing robust induction of myofibroblast phenotype following TGF- $\beta 1$ treatment. (C) Western blotting and densitometry provide quantitative validation of myofibroblast differentiation $\left(\alpha-\mathrm{SMA}^{+}\right)$only in the presence of TGF- $\beta 1$ cytokine. $n=3$ /group. 


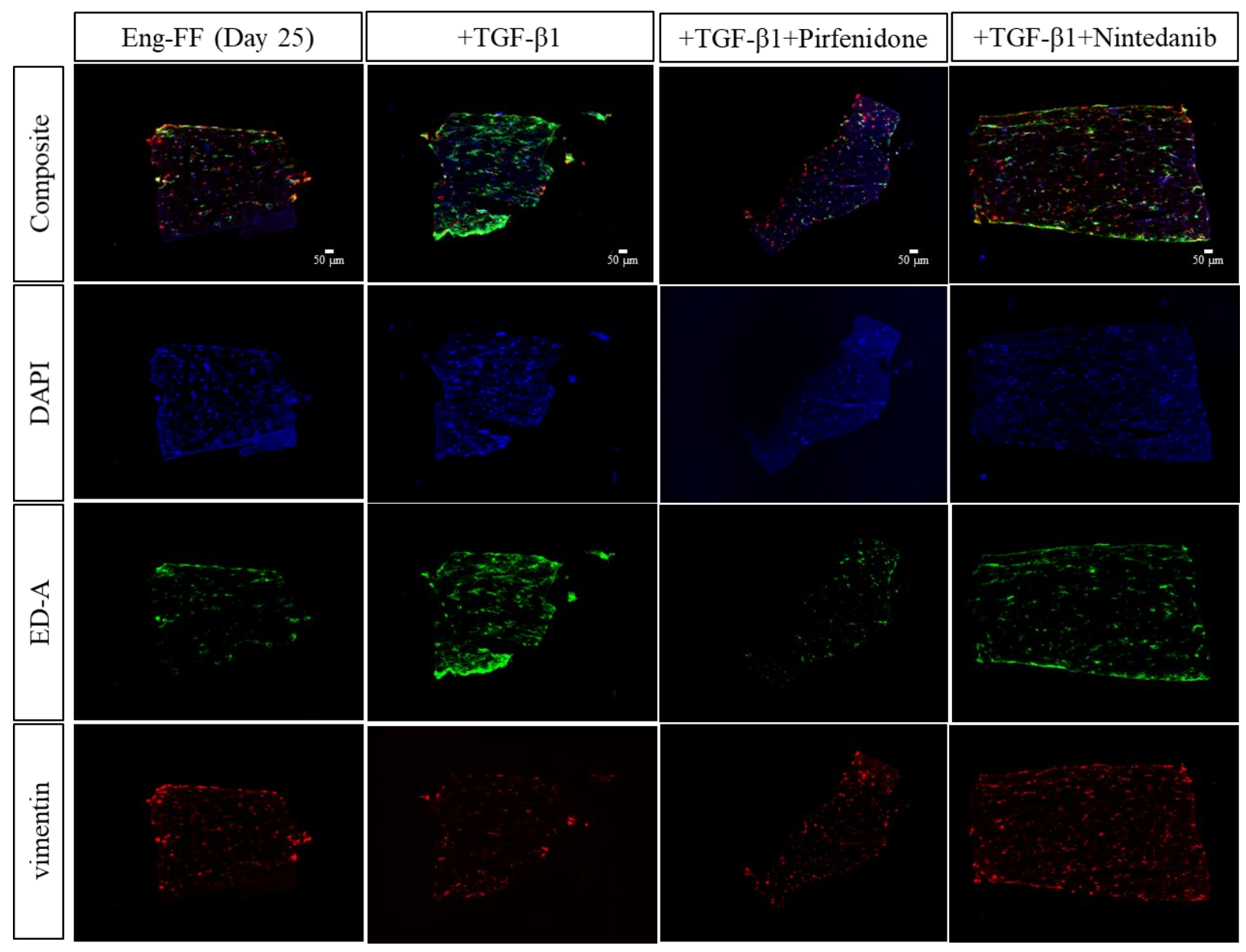

Figure S10: Detailed channel-by-channel signal of Figure $5 \mathrm{Ba}$, displaying individual signals from DAPI, ED-A and vimentin staining. 


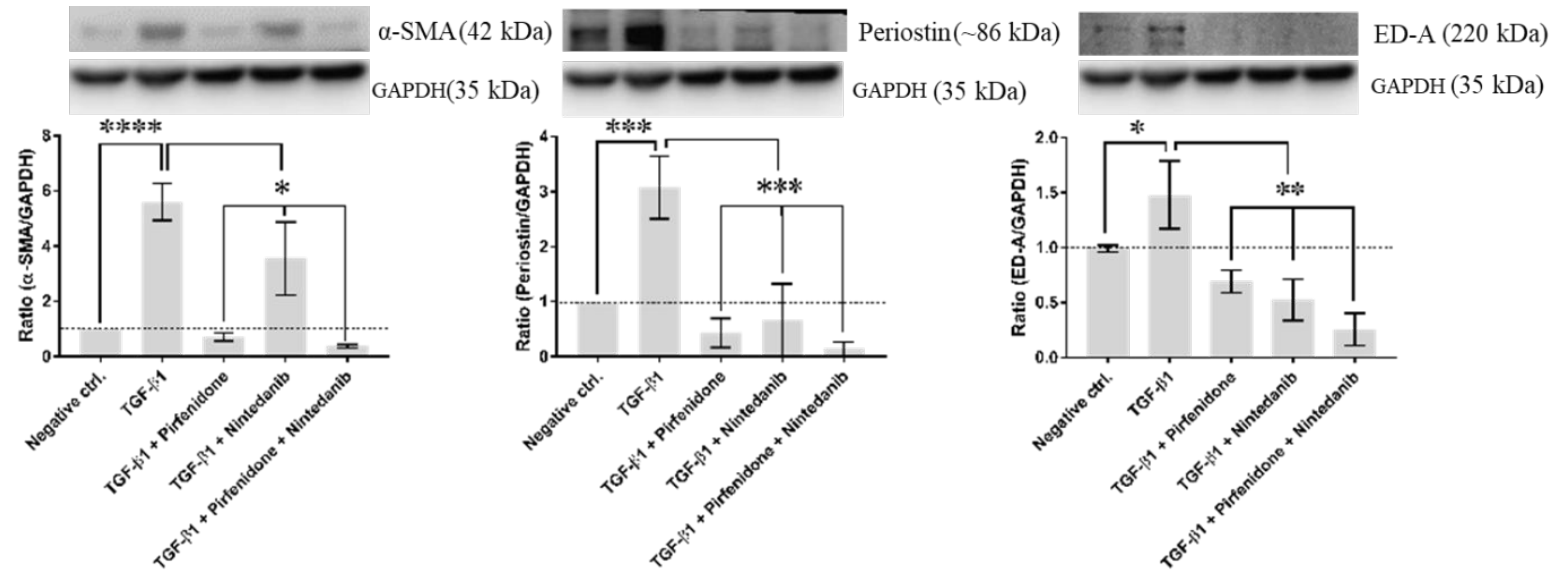

Figure S11: Anti-fibrotic drug testing on 2D fibroblast cultures (A) Western blotting for myofibroblast markers ( $\alpha$-SMA, periostin, -ED-A) following treatment with anti-fibrotic drugs pirfenidone and nintedanib. $\mathrm{n}=3$ /group. 


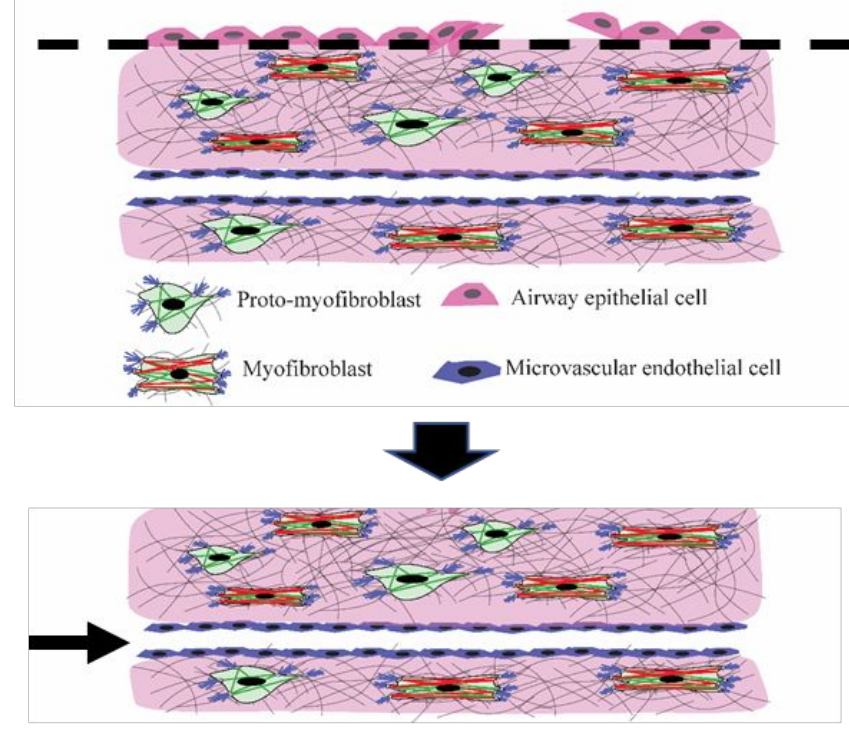

\section{Scrape epithelial monolayer from surface}

\section{Perfuse trypsin containing media to selectively remove endothelial cells}

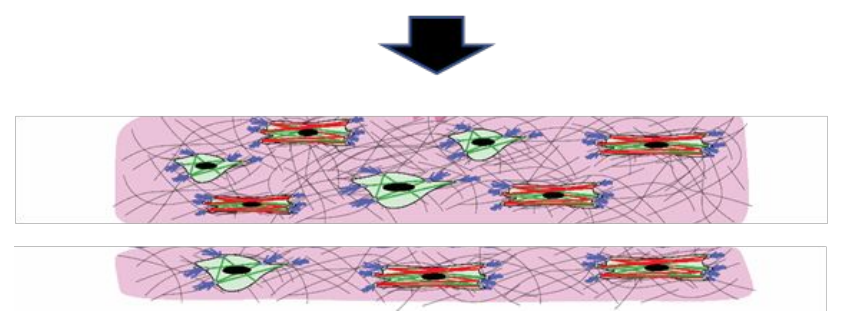

\section{Process left over hydrogel to collect fibroblasts}

Figure S12: Eng-PF tissues could be post-processed for protein/RNA analysis in the following way to reduce cross-contamination of proteins/RNA from different cell types. 